Review Article

\title{
In Vivo Anti-Candida Activity of Phenolic Extracts and Compounds: Future Perspectives Focusing on Effective Clinical Interventions
}

\author{
Natália Martins, ${ }^{1,2}$ Lillian Barros, ${ }^{1}$ Mariana Henriques, ${ }^{2}$ \\ Sónia Silva, ${ }^{2}$ and Isabel C. F. R. Ferreira ${ }^{1}$ \\ ${ }^{1}$ Mountain Research Centre (CIMO), ESA, Polytechnic Institute of Bragança, Campus de Santa Apolónia 1172, \\ 5301-855 Bragança, Portugal \\ ${ }^{2}$ Centre of Biological Engineering (CEB), Laboratório de Investigação em Biofilmes Rosário Oliveira (LIBRO), \\ University of Minho, Campus de Gualtar, 4710-057 Braga, Portugal \\ Correspondence should be addressed to Sónia Silva; soniasilva@deb.uminho.pt and Isabel C. F. R. Ferreira; iferreira@ipb.pt
}

Received 2 April 2015; Revised 30 July 2015; Accepted 6 August 2015

Academic Editor: Peter Fu

Copyright (C) 2015 Natália Martins et al. This is an open access article distributed under the Creative Commons Attribution License, which permits unrestricted use, distribution, and reproduction in any medium, provided the original work is properly cited.

\begin{abstract}
Candida species have increasingly deserved a special attention among the medical community. In spite of the presence of Candida species as a human commensal, alarming rates of local and systemic infections have been observed, varying from moderate to severe impact. Currently available antifungal drugs have progressively lost their effectiveness, pointing urgently the problem of the microorganisms with acquired-resistance. Natural matrices are secularly used for numerous purposes, being inclusive and highly effective as antimicrobials. Increasing evidence gives a particular emphasis to the contribution of phenolic extracts and related individual compounds. In vitro studies clearly confirm their prominent effects, but the confirmation through in vivo studies, including the involved mechanisms of action, is not so much deepened. Therefore, the present report aims to provide extensive knowledge about all these aspects, highlighting the most efficient phytochemical formulations, including therapeutic doses. Further studies need to be incited to deepen knowledge on this area, namely, focused on clinical trials to provide safer and more effective antimicrobials than the current ones.
\end{abstract}

\section{Introduction}

Over the last years, plant-derived extracts and related phytochemicals have gained a particular attention by scientific researchers, due to their healing effects [1-3]. Studies involving the elucidation of their mechanisms of action, including pharmacokinetics and pharmacodynamics, have been also performed [4-8]. In the last two decades, among its phytotherapeutic properties, the antimicrobial potential, namely, anti-Candida effects, has deserved a particular attention. In fact, Candida species have been implicated in an onset of mild and severe clinical conditions, although it was considered a commensal microorganism of healthy individuals [9].

In the majority of cases, patients have no infection signals and symptoms manifestation; thus, upon a clinical diagnosis, a severe colonization and related infection are installed [9]. Antifungals and even other antimicrobial drugs are, therefore, extensively prescribed; but the present condition is much more complex than simple Candida species overgrowth [9]. Other triggering factors are also involved, which are neither considered nor regulated by the antimicrobials. Obviously, recurrent infections will be installed, leading to the appearance of microorganisms highly resistant to conventional antifungal drugs [10-12].

Plants and all living organisms produce countless substances aiming at their survival, defence, nutrition, and even growth [13-15]. Regarding their antimicrobial properties, namely, antifungals, some of them have already been described. Phenolic compounds, namely, phenols, flavonoids, coumarins, quinones, saponins, and xanthones, are the most abundant, besides alkaloids, lectins, polypeptides, 
terpenoids, and essential oils [15-18]. In vitro studies are crucial to screen their effects [19], security, efficiency, and other biochemical parameters, but plant-derived bioactive molecules possess several modes of action, establishing synergic, antagonist, and polyvalent relationships with other compounds, besides suffering chemical changes due to organic metabolism, including the effects on gut microbiota $[5,20,21]$. Those features could not be assessed through in vitro and, therefore, in vivo studies, and mostly clinical trials shall be also considered.

In this sense, the present report intends to provide extensive knowledge on in vivo anti-Candida potential of phenolic extracts and compounds. Furthermore, the in vivo mechanisms of action of the previous will be presented, as well as potential clinical applications (i.e., galenical formulations, among others).

\section{Candida Species: Clinical Impact}

2.1. Epidemiological Features. Microorganisms are ubiquitous and, in adequate concentrations, are crucial to the organic homeostasis. To ensure this equilibrium, friendly microbiota, gastrointestinal $\mathrm{pH}$, immune system, and organic metabolism play a role of the utmost importance [22, 23]. Nevertheless, daily routine, environmental factors, and people lifestyles, among other factors, act as triggers to unbalance. Additionally, higher levels of stress, the overuse of antibiotics, antacids and proton-pump inhibitors, birth control pills or steroids, the exposure to environmental chemicals, and wrong food choices (namely, diets with too many sugars, alcohol, and fermented products) are encountered between the most common causes of dysbiosis. Much more than a "dys" (which means not) and "symbiosis" (which means living together in mutual harmony), dysbiosis reflects the relationship between microbes and the host [22, 23]. In contrast with some high-virulence microorganisms that cause immediate reactions, low-virulence microorganisms are insidious. Candida species, considered a commensal microorganism, comprises an excellent example [22-24]. Among them, C. albicans is encountered as the most frequent, being responsible for approximately 50-90\% of cases of human infection (candidiasis) [9]. But presently, other nonalbicans Candida species have also been involved, mainly C. tropicalis, C. glabrata, C. dubliniensis, and C. parapsilosis. Besides their associated virulence features, they are also able to form biofilms with other species, which not only makes their eradication difficult but also improves their prevalence and related resistance to antimicrobials [9, 25]. Thus, and despite providing several benefits to the host, they possess a higher adaptability and numerous strategies to survive, which not only favors their overgrowth but also changes their susceptibility profiles. The human organism is colonized by these yeast species at, or near, birth, mainly through a physical contact with the vaginal flora [25-27]. Under normal physiological conditions, Candida species are present in small amounts, but some individual characteristics determine the probability of Candida overgrowth and, consequently, establishment of infection. For example, women are most susceptible, as hormonal variations act as triggering factors, but men could also be affected [9, 28].

Previous to the synthesis of chemical drugs, namely, antibiotics and other antimicrobials, microorganisms naturally produce natural biocides towards each other, but also establishing symbiotic relationships [22, 29, 30]. Nevertheless, due to the disseminated adhesion to the use and overuse of antibiotics, not only in humans but also in animals, numerous microorganisms with undergoing mutations have appeared, and linked with this, the rates of chronic and degenerative problems soared in an exponential manner.

2.2. Drug Resistance. A large amount of antimicrobial drugs, such as antibiotics and antifungal agents, is currently available to fight against a wide variety of infectious syndromes [31,32]. Once these drugs act in a nonspecific way, they kill not only harmful but also helpful microorganisms, including healthy microbiota, apart from interfering with several metabolic pathways $[22,29,30]$. As previously mentioned, opportunistic microorganisms may be present in small amounts in healthy organisms, without causing any clinical disturbance or infectious symptoms. But, unfortunately, in the last decades, in the face of a minimal symptom of infection, antimicrobial drugs are widely prescribed, mostly without determining the causative agent. The fact that unbalanced diets and nutrient deficiencies are important secondary causes of infection is completely ignored [22, 30]. In fact, several nutrients are crucial to maintain a healthy immune system $[22,23,32]$. So, it is easy to understand that, in the face of nutritional deficits, the defense system cannot work properly, and so the probability of occurrence of opportunistic infections and other organic disorders is significantly improved.

In the face of the higher rates of microorganisms with acquired drug resistance, among which are Candida speciesrelated infections, scientific advances regarding new synthetic drugs, more specific and effective than the previous, have been supported by pharmaceutical industries. The current ones are ineffective not only at higher doses but also in drug combination [10, 33-35]. The most prominent situation is the acquired-resistance to azoles, mainly by enhancement of its efflux through upregulation of multidrug transporter genes on yeast cells, besides changes in the ergosterol biosynthesis and occurrence of mutations. The new synthetic drugs seem to be effective against the majority of insidious- and resistantCandida species [35-40], but the problem of their side effects and related toxicity still remains.

2.3. Upcoming Approaches. Plants comprise an extremely rich pool of bioactive constituents [41-45]; most of them are secondary metabolites (final or intermediate products) [14, 45-47]. Among them, phenolic compounds have gained a special attention in the last years. In fact, numerous studies have pointed their prominent antifungal potential $[16,45,46$, 48-50].

The use of botanical preparations is an ancient practice, but without a solid scientific basis, it is poorly accepted 
by the medical community. Numerous underlying interests have blocked its worldwide recognition, in spite of its evident effectiveness and absence of side effects and toxicity, when properly used. It is a fact that several studies have reported problematic herbal-drug interactions [51-53], but it is very important to highlight that the majority of synthetic chemicals are derived from plants, that they act on symptoms and not in the predisposing cause(s), that they only possess one or another therapeutic indication, and that the magnitude of side effects and toxicity is directly related with the prescribed dosages $[22,32]$. On the other hand, natural matrices, besides providing a wide variety of phytotherapeutic properties, improve and even contribute to a proper nutritional balance $[22-24,54]$. Furthermore, these bioactive molecules show a higher spectrum of clinical applications, due to the occurrence of synergic, antagonistic, and polyvalence reactions; their side effects and related toxicity disappeared and/or are neutralized, as well as being able to favor the organic homeostasis, providing not only immunomodulatory and healing properties, but also other health benefits $[22,23,55]$. Thus, while botanical preparations act in a holistic manner, the chemical drugs mainly block one or more metabolic pathways improving the organic unbalance [22-24, 32]. Among the intensive research on this area, in vitro studies clearly assume the leadership, while in vivo studies remain secondary. Notwithstanding, in vitro studies have clear limitations, Notwithstanding, in vitro studies have clear limitations; so, apart from the discovery of potentially effective alternatives, is also important to analyze its feasibility and to access the involved modes of action, through in vivo studies.

\section{Clinical Importance of In Vivo Studies}

3.1. Historical Perspective. The diagnosis of an infection comprises several levels of complexity, and currently the idea that the presence of some microorganisms is inoffensive was changed completely $[56,57]$. In particular, opportunistic microorganisms, including Candida species, can cause from a simple catheter-related fungemia or peritonitis to severe localized infections, or even extensive hematogenous dissemination $[9,57,58]$. Immunocompromised patients, transplanted or submitted to broad surgeries, individuals with neoplastic diseases, and children and elderly people are considered as a higher risk population, being much more vulnerable than other common citizens $[9,58]$. In this sense, and considering that in some cases neither signals nor symptoms are observed, it is crucial to establish a correct diagnosis, which implies not only the use of representative isolated clinical material, but also the isolation and identification of the involved microorganism, towards a correct clinical intervention $[56,57]$.

In the first stages of the clinical investigation, in vitro techniques (such as microscopic, serologic, antigenic, amplification, and susceptibility tests) are extremely useful, but it is necessary to highlight that they do not consider numerous variables, namely, the individual idiosyncrasies and organic metabolism. Thus, and regarding the latest advances related with the opportunistic fungal infections, numerous in vitro studies have been carried out, including the screening of some natural extracts (e.g., rich in phenolic compounds) with anti-Candida potential [19], but also evaluating their mechanisms of actions and other laboratorial parameters (i.e., proteomic, genetic, molecular studies, etc.) $[5,6,50,59$, 60]. Notwithstanding, in vivo studies still remain scarce.

3.2. In Vivo Antifungal Potential of Phenolic Extracts. Table 1 shows the phenolic extracts with reported in vivo activity against Candida species. Combretaceae followed by Acanthaceae are the most studied plant families. Considering the obtained results, leaves, followed by the seeds and fruits, and then flowers appear as the most enriched-plant parts. In fact, leaves and seeds/fruits show higher levels of phenolic compounds, but their concentrations depend greatly on the growth, harvesting, and storage conditions [6164]. Additionally, the extractability of phenolic compounds depends on the type of solvent used [19]. Methanol, followed by acetone, water, ethanol, petroleum ether, methanoldichloromethane, ethyl acetate, and n-butanol encounter between the most frequently used extraction solvents. In fact, these solvents were also the most commonly used in the in vitro studies dealing with anti-Candida potential of phenolic extracts [19].

The neutrophils adhesion, locomotion, and chemotaxis tests, as well as the assessment of their phagocytic activity to kill $C$. albicans, have been some of the parameters used to evaluate the activity of phenolic extracts against Candida species $[65,66]$. The obtained results allow not only the determination of the abundance of neutrophils in blood samples, in terms of number of total leukocyte cells (TLC) and differential leukocyte cells (DLC), but also the analysis of the efficiency/capacity to kill C. albicans. Haemagglutinating antibody (HA) titre and delayed-type hypersensitivity (DTH) response tests have been also carried out [67]. The obtained results from these tests can be considered direct indicators of the status of the immune system and also allow the determination of the immunomodulatory potential of the studied substances. The humoral immune response presupposes the existence of phagocytic activity but also includes other immune-related organic reactions, such as induction of synthesis, reproduction, and differentiation of defense cells. In this sense, the previous assays give specific information related with the activity and efficiency of organic-defense cells to ingest, to remove, and to destroy not only microorganisms, but also malignant cells, inorganic particles, and altered tissues.

Evaluation of the wound healing potential, for example, through measuring the tensile strength, exudate, lesion size, crust formation, and also histological and histopathological examinations, has been applied by some authors [68-75]. In fact, the colonization of wounds by microorganisms is very common; thus, it is extremely useful to discover plant extracts with pronounced abilities to improve, for example, wound closure and crust formation. Among the wide variety of plant's secondary metabolites, flavonoids, but specifically tannins, have marked astringent, antioxidant, and 


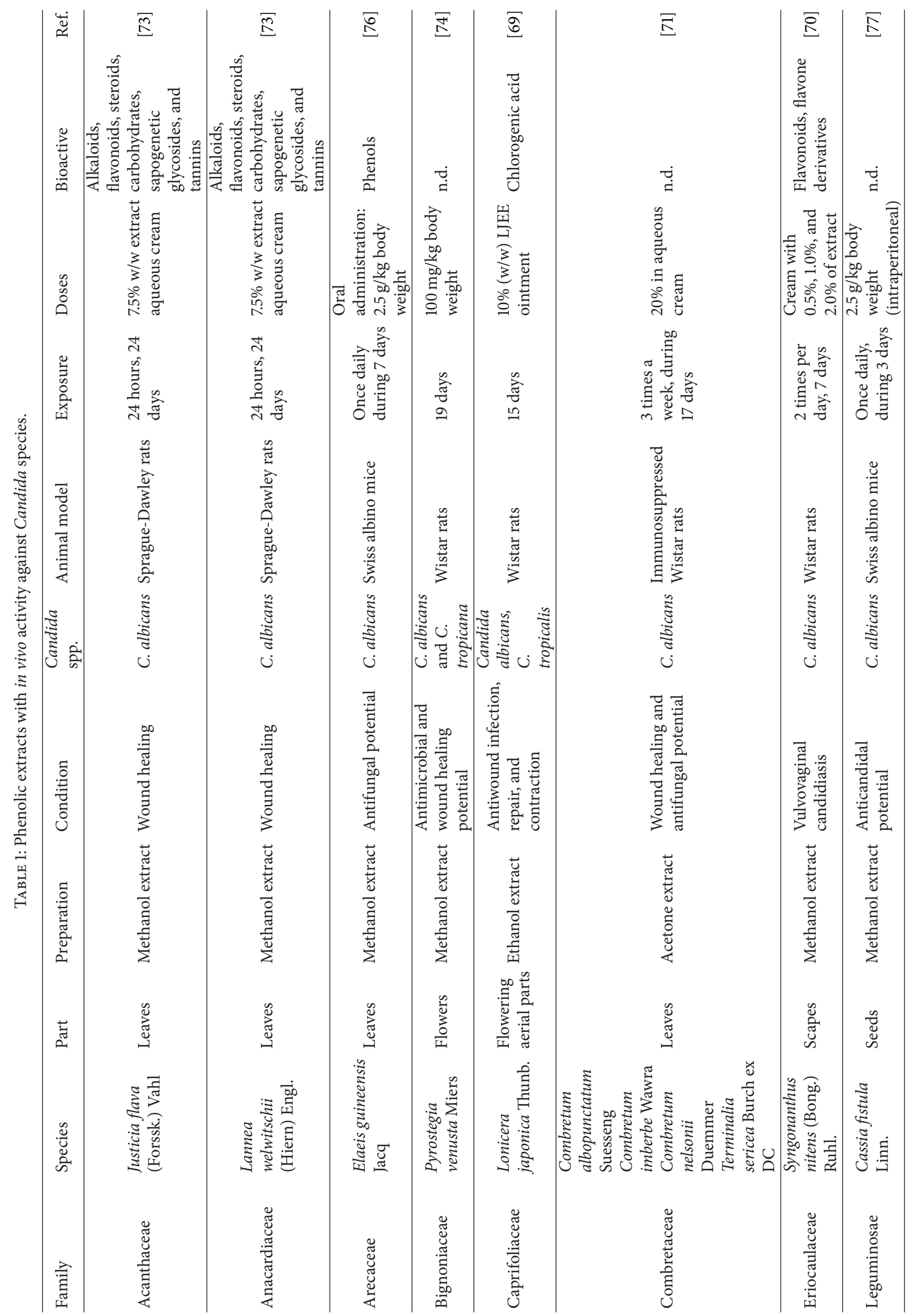




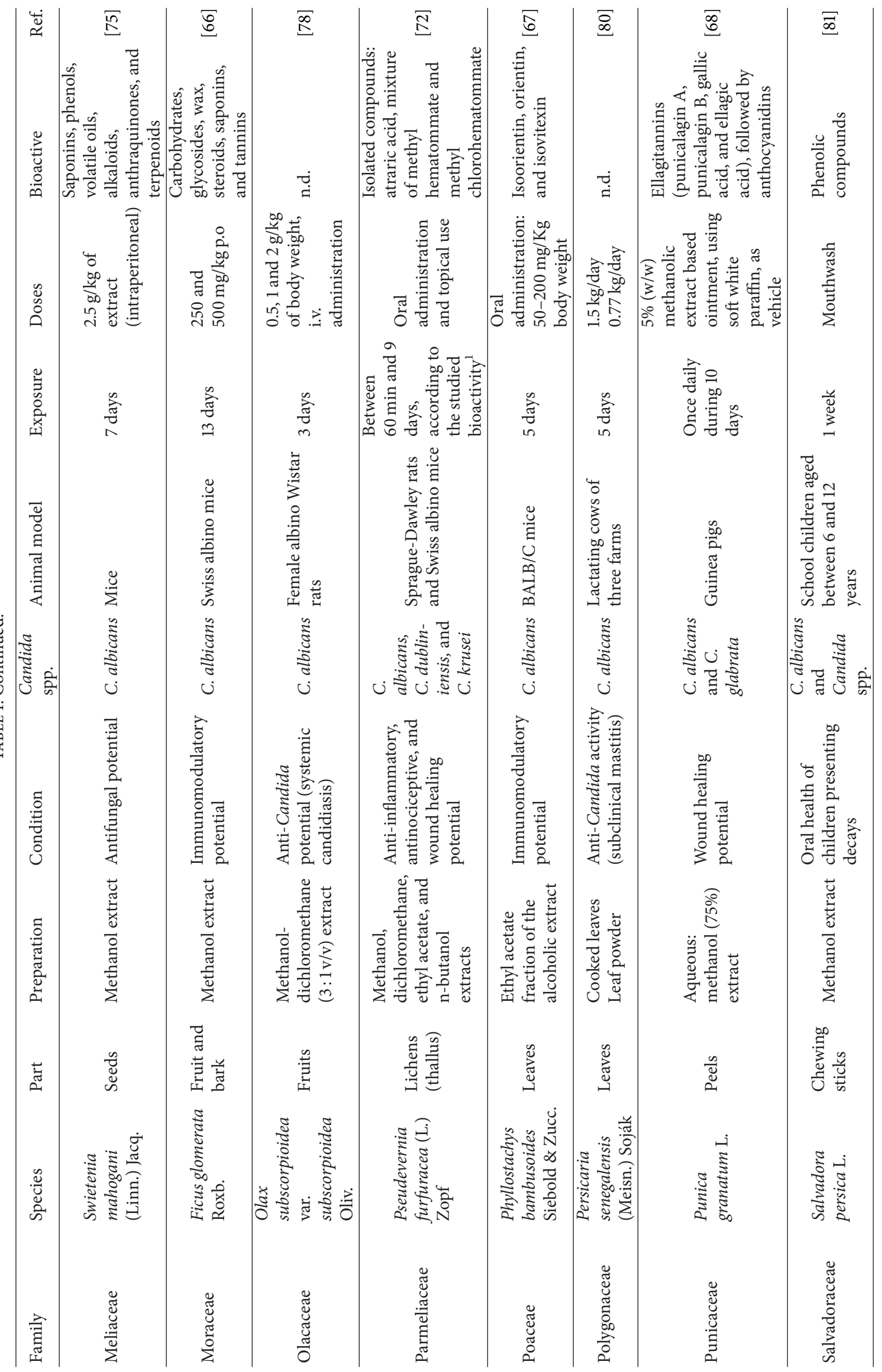




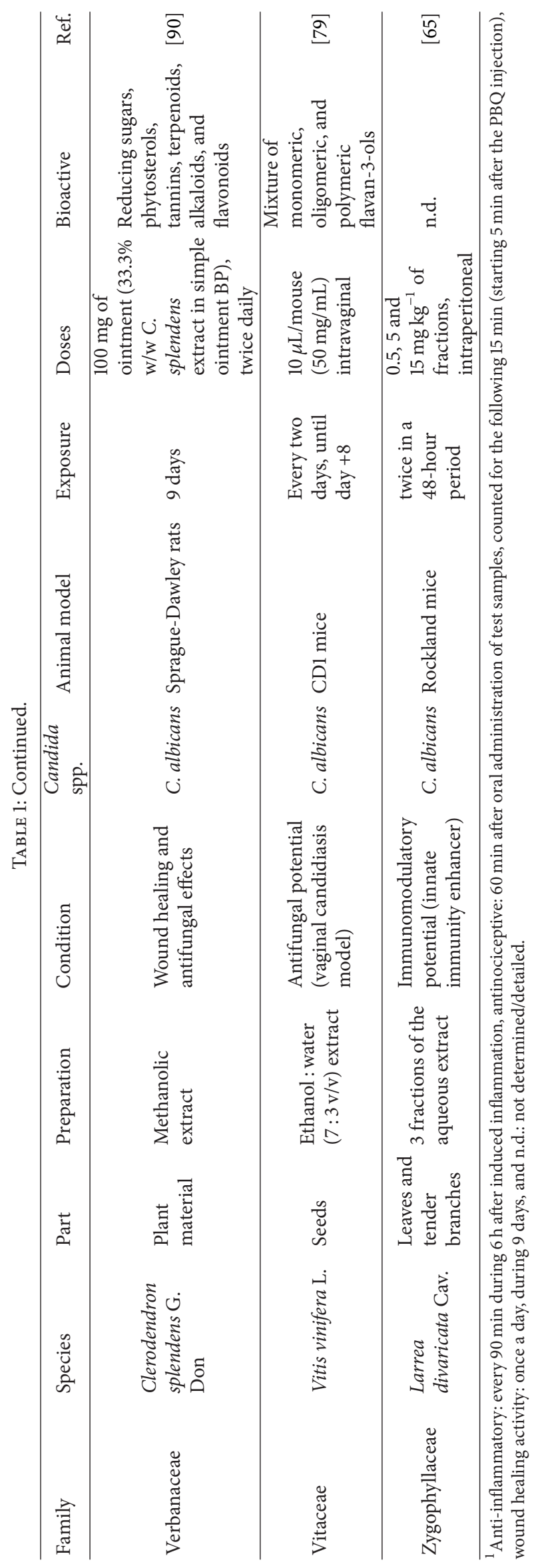


also antimicrobial potential and, therefore, a direct influence in wound contraction and healing potential $[69,73]$.

The evaluation of the efficiency/efficacy of plant extracts in induced systemic and local infection models is a very interesting approach, once it mimics the real conditions of infected organisms and, at the same time, the achievement of the direct effect of the tested substances. Vijayarathna et al. [76], Jothy et al. [77], Sahgal et al. [75], and Dzoyem et al. [78] evaluated the effects of plant extracts in systemic infections, while Araújo et al. [70] and Simonetti et al. [79] in induced vaginal infection, Abaineh and Sintayehu [80] in local mastitis, and, lastly, Chelli-Chentouf et al. [81] in oral health and improvement decays in children.

Although the aim of the present report is to highlight the in vivo anti-Candida potential of phenolic extracts and compounds, it should be noticed that natural matrices possess much more than a single bioactivity and that the sum of several bioactivities might result in a different final clinical application. Furthermore, a unique bioactive potential (conferred by a specific or several chemical compounds) is able to improve considerably other bioactive effects. For example, several reports have shown that plant extracts with a significant antioxidant potential also evidence considerable antiinflammatory and antimicrobial effects [42, 82-85]. Besides, plant extracts with higher antifungal potential normally exert significant immunomodulatory and also antiseptic effects. Thus, and in the same line with the results of several authors, plant extracts that present a considerable healing potential have also a great antioxidant, antiseptic, and antimicrobial activities. Phenolic compounds are the most representative chemical compounds with the above-described bioactive properties, but due to the slight number of in vivo studies reporting their anti-Candida potential, few conclusions can be stated. Beyond that, $C$. albicans is the main focus of the present studies, but other non-albicans Candida species should be also considered once present in different infections.

\subsection{In Vivo Antifungal Potential of Individual Phenolic} Compounds. Table 2 shows the in vivo antifungal potential of phenolic compounds against Candida species. Stilbenes, namely, pterostilbenes and riccardin $\mathrm{D}$, are the most studied phenolic compounds with anti-Candida potential, followed by curcuminoids (curcumin and piperine). Its respective chemical structures are shown in Figure 1. Among the tested stilbenes, pterostilbenes evidenced a higher anti-Candida biofilm activity than the riccardin. Li et al. [86] observed a total inhibition of the biofilm formation by using concentrations of $32 \mu \mathrm{g} / \mathrm{mL}$ and $64 \mu \mathrm{g} / \mathrm{mL}$ of pterostilbenes; at $16 \mu \mathrm{g} / \mathrm{mL}, C$. albicans biofilms were defective and only sparse cells were founded. In contrast, the same authors [87], evaluating the effect of riccardin $\mathrm{D}$ on anti-Candida biofilm formation, did not observe a complete growth inhibition by using a concentration of $64 \mu \mathrm{g} / \mathrm{mL}$.

Concerning the evaluation of the antifungal potential of curcuminoids, Sharma et al. [88] showed that the use of curcumin alone provides an insignificant effect, due to its poor bioavailability, but when administered in association with piperine, an inhibitor of the hepatic and intestinal glucuronidation, its efficacy, and related antifungal efficiency was completely changed. For example, the antifungal potential of associated substances, curcumin $(100 \mathrm{mg} / \mathrm{kg})$ in combination with piperine $(20 \mathrm{mg} / \mathrm{kg})$, presents a similar potential to the current antifungal drug fluconazole (50 mg/kg).

Nevertheless, considering the scarce number of studied phenolic compounds, no solid conclusions can be proposed. Additionally, commercial standards are encountered as the most studied, alternative to the plant-derived phenolic compounds. Candida albicans continues to be the most focused Candida species, but concerning the real clinical conditions, for example, catheter infections and systemic infection models, other non-albicans Candida species should be also considered. Rats, particularly albino and immunocompromised, have been the mostly used animal models due to not only their higher susceptibility to infections, but also weak efficiency of their immune system and polymedication. Per se, the multidrug administration is an isolated triggering factor that gives higher vulnerability to organisms. In the same line, several classes, ways of administration, and infection models should be also studied, by inducing oral cavity, bloodstream, and vaginal, ocular, nails, and skin infections, once they are the most commonly effected tissues by these yeasts. Furthermore, the prophylactic effect of plant extracts (e.g., phenolic extracts) and related individual compounds should be also considered. In fact, the prevention of fungal infections might be as important as the therapeutic intervention.

Considering all the above described features, more detailed studies should be carried out, aiming not only at a better comprehension of the present problematic conditions, but also at providing new and more effective alternative treatments (including a prophylactic approach) and, lastly, at giving consistent data and specific tools towards a future approach regarding clinical trials.

\section{Anti-Candida Species Inherent Mechanisms of Action}

Although several studies have been carried out evaluating the antifungal mechanisms of action of natural matrices and isolated compounds, the experimental studies involving phenolic matrices with evidenced in vivo anti-Candida potential are considerably scarce. Among the in vitro determined anti-Candida potential of natural matrices, the effects on the immune system, namely, macrophage activation and upregulation of the expression of receptors related with phagocytosis, were one of the most accessed mechanisms [65]. Martino et al. (2011) concluded that the studied fractions of the aqueous extract of Larrea divaricata Cav. improve the superoxide anion production and, consequently, increase the phagocytosis of $C$. albicans and improved the nitric oxide (NO) production when compared with controls. Those fractions evidenced not only a direct action on macrophage activation, but also an indirect effect on production and releasing of ROS and NO, which enhanced the destruction of the invaders. On the other hand, Roy et al. [74], evaluating the antimicrobial and wound healing potential of Pyrostegia venusta Miers, proposed that the evidenced healing effects 


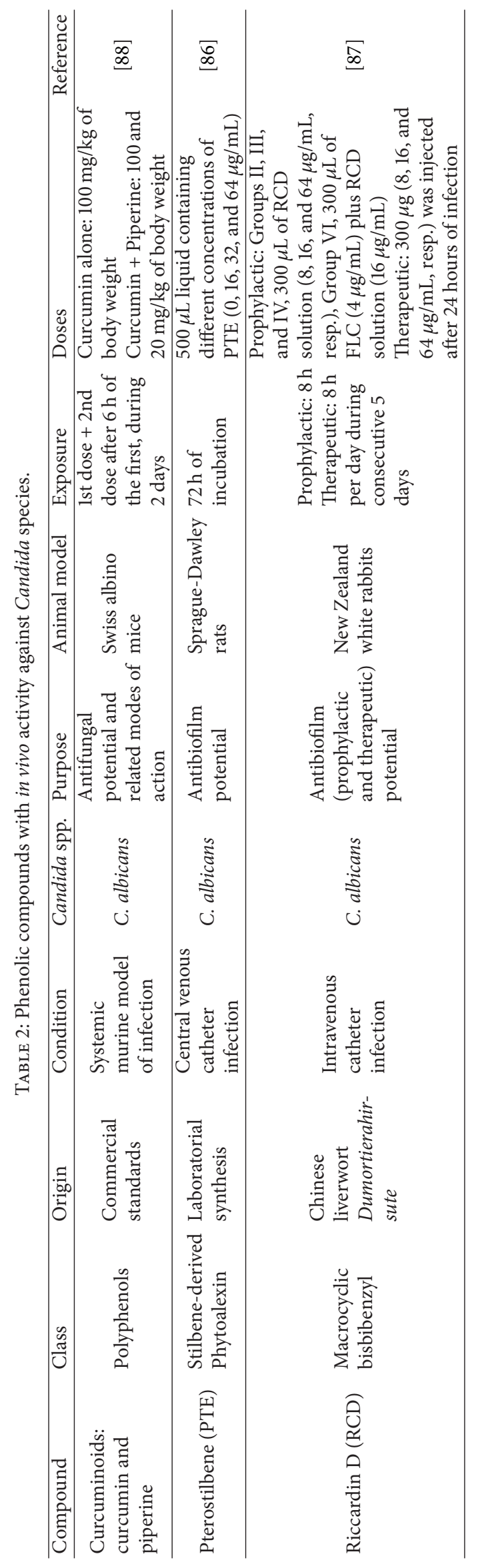


<smiles>COc1cc(/C=C/C(=O)/C=C(O)/C=C/c2ccc(O)c(OC)c2)ccc1O</smiles>

Curcumin<smiles>Oc1ccc(CCc2ccc(CCc3cccc(O)c3CCc3ccc(Oc4ccccc4)cc3)cc2)cc1</smiles><smiles>CCCC=CC=Cc1ccc2c(c1)OCO2</smiles><smiles>CCCCCCCCCCCCCCCCO</smiles>

FIGURE 1: Chemical structures of the tested bioactive molecules with in vivo anti-Candida potential.

were related with the accumulation of the anti-inflammatory and proinflammatory cytokines and cells of immune system, particularly monocytes and macrophages, as also due to the antimicrobial effects of the tested natural matrix in the local of the tissue injury. In addition, Chen et al. [69], evaluating the wound healing and anti-inflammatory potential of Lonicera japonica Thunb. and related mechanism of wound contraction, concluded that these effects were mainly attributed to the improvement of collagen and granulation tissue formation, fibroblast proliferation, angiogenesis, and consequently stimulation of the reepithelialization. Furthermore, the authors proposed that these effects were also due to the existence of synergistic effects between antimicrobial and anti-inflammatory properties of the active ingredients, including chlorogenic acid.

Kumar et al. [67] evaluating the immunomodulatory potential of Phyllostachys bambusoides Siebold \& Zucc, concluded that the observed effects were mainly due to the upregulation of the macrophage activation and, consequently, induction of the phagocytic activity. The observed effects were in part derived from the improvement of NO production. These facts resulted in a significant increase of the macrophage phagocytic activity of Candida species as well as in a promotion of the proliferation, maturation, and improvement of the immunological function of other immune defense cell types, resulting in an effective eradication of the invaders.

Otherwise, the effects of the phenolic extracts could be exerted directly in Candida species, instead of in the host individuals. Figure 2 shows the most common sites of action of the antifungal drugs. The interaction with the fungal membrane and its specific components has been described as one of the most common targets of natural matrices.

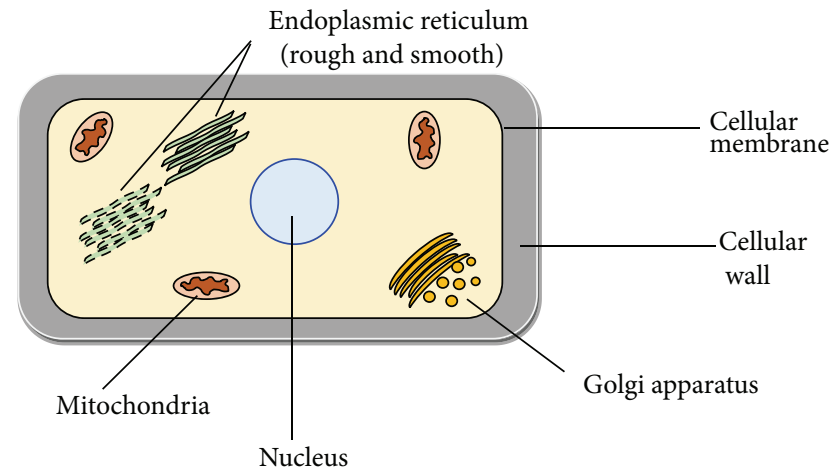

FIGURE 2: Mechanisms of action of the in vivo tested phenolic extracts and compounds against Candida species.

Associated with an increasing number of resistant-Candida species to the conventional antifungal agents, and reminding the predominance of critical infections, the discovery of new and effective alternatives is of the utmost relevance. It is a fact that several antifungal agents, such as azoles (e.g., fluconazole) and others that interact with fungal membrane, mainly exert fungistatic effects, despite their current higher rates of inefficiency. Among the reports about the antiCandida activity of plant extracts, the associated modes of action of those plant extracts and even isolated compounds have been increasingly clear. For example, Jothy et al. [77] described a higher anti-Candida activity of the methanol extract of Cassia fistula Linn. seeds and carried out an evaluation of the mechanisms of action, by scanning electron microscope (SEM) and transmission electron microscope (TEM) observations. The authors verified that, in comparison 
with controls, treated cells presented a significant small size, irregular shape, with cell wall modifications, and clear depressions on the cell surface with holes. Furthermore, and after $12 \mathrm{~h}$, the leakage of ions between treated and untreated cells appears to be the same; between 12 and $36 \mathrm{~h}$, a significant increase in $\mathrm{K}^{+}, \mathrm{Ca}^{2+}$, and $\mathrm{Mg}^{2+}$ leakage has occurred in the treated cells. It means that, during the first $12 \mathrm{~h}$, the applied extract exerts a little effect on the cell membranes but, after this time, its disruption associated with an important surface alteration and related damage were observed. As proposed by the authors, the anti-Candida activity of $C$. fistula may occur by two main modes: firstly, a passive entrance of the seeds extract into the plasma membrane, initiating the membrane disruption and, then, by the accumulation of the C. fistula seeds extract in the plasma membrane that results in cell growth inhibition.

Concerning to the mechanisms of action of isolated phenolic compounds, Li et al. [86], evaluating the activity of pterostilbene (PTE), a stilbene-derived phytoalexin, against C. albicans biofilms formation, observed a dose-dependent antibiofilm effect from the PTE concentration used. These achievements were mainly due to the disruption potential, induction of filamentous defects, and reduction of the cell density. In addition, the authors assessed the effect of PTE on gene expression and observed that, at $16 \mu \mathrm{g} / \mathrm{mL}, 307$ genes were differentially expressed: 193 were downregulated and 114 were upregulated. The observed downregulated genes were mainly related with the process of ergosterol biosynthesis, function of oxidoreductase activity, and components of the cell surface, while the upregulated genes were related with the process of protein unfolding (heat shock proteins). RAS1 (the RAS signal transduction GTPase gene), ECE1 (cell elongation protein gene), SAP5 (secreted aspartyl proteinase gene), SAM2 (S-adenosylmethionine synthetase gene), PGA10 (involved in cell surface), and ERG11 (involved in the ergosterol biosynthesis) are some of the downregulated genes. On the other hand, ESC4 (related with the inhibition of biofilm formation), YWP1 (encoding yeast cell wall protein), CEK1 and RIM8 (involved in filamentation), and HSP78 (involved in protein unfolding) were found among the upregulated genes. Furthermore, the authors described that the PTE also exerts an effect on the Ras/cAMP pathway, once after the PTE treatment and the exogenous cAMP restored the yeast-to-hypha morphological transition, and they also concluded that PTE was able not only to inhibit the biofilm formation but also to destroy the maintenance of mature biofilms. Lastly, by studying the in vivo antibiofilm potential of PTE, the authors confirmed all of the above proposed theories and also observed that PTE presents a high bioavailability and no toxicity on the tested mice models [86].

In the same line, Sharma et al. [88], studying the in vivo antifungal potential of curcumin and its mode of action, concluded that curcumin acts by mediating the ROS signaling pathway and, consequently, stimulates the proapoptotic regulatory processes by increasing the number of preapoptotic cells. Notwithstanding, the authors also described that the addition of an antioxidant could prevent these effects. Furthermore, it was showed that curcumin modulated the drug efflux of yeast $\mathrm{ABC}$ transporters without affecting the levels of transcription genes encoding these transporters. A block of the hyphae growth was also reported by the authors, not only in C. albicans but also in other non-albicans Candida species, and in this case, the addition of antioxidants could not reverse the inhibitory effect. Lastly, the authors verified that curcumin targeted the global repressor TUP1 (thymidine uptake 1) which, in an independent manner of ROS production, prevented the hyphae development, in both liquid and solid hypha-inducing media [88].

Taking into account the above-described mechanisms of action of phenolic extracts and related individual compounds, it is feasible to conceive that plant extracts could be promisor antifungal agents. Moreover, no toxicity was found to the majority of the tested phenolic matrices, which itself opens new perspectives for the future approach as new antiCandida leaders.

\section{Current Phytochemical Formulations}

Several phytochemical preparations are currently available, for either external or internal uses [89]. Creams, lotions, powders, sprays, and ointments are mainly directed for cutaneous mycosis and onychomycosis, while suspensions, capsules, drops, or suppositories have been used for mucous infections.

Table 3 shows the most frequent in vivo phytochemical preparations for intraperitoneal, intravaginal, intravenous, oral, and topical uses. Oral administration, followed by topical, intraperitoneal, intravaginal, and intravenous administrations, is one of the most common administration ways. For oral administration, several types of suspensions, aqueous solutions, direct-plant extract application, and mouthwashes were also tested. In relation to mouthwashes, toothbrushes with toothpaste and interdental cleaners are, currently, the most common procedures in order to maintain a correct oral hygiene. However, and despite some mouthwashes and mouthrinses being also available, alcohol is commonly used in order to ensure a correct dissolution of the active ingredients. Its use has been questioned because the alcohol-containing mouthwashes induce desiccation of the oral mucosal membranes. Thus, it is very important to prevent, reduce, and even treat plaque microbial-associated diseases but also to ensure that the used preparations are naturally safe and efficient. In this sense, a mouthwash solution was applied by Chelli-Chentouf et al. [81] in a children's school, in order to evaluate not only its efficiency but also its stability and physicochemical parameters.

Creams and ointments are the most studied formulations for topical use in fungal infections, mainly in cases of local affections, such as excision and incision wounds, and vaginal infection models. In the last case, intravaginal administration is the highly indicated, as also cream, solution, or even suspension $[70,79]$. Nevertheless, other phytochemical preparations have also been administered in laboratorial models, namely, by intraperitoneal $[65,75,77]$ and intravenous [78] ways. 
TABLE 3: Phytochemical preparations evaluated through in vivo laboratorial models.

\begin{tabular}{|c|c|c|c|}
\hline Application & In vivo model & Type of formulation & Reference \\
\hline \multirow{3}{*}{ Intraperitoneal } & Immunomodulation & Solution (water) & {$[65]$} \\
\hline & \multirow{2}{*}{$\begin{array}{l}\text { Intravenous Candida } \\
\text { infection }\end{array}$} & Solution (methanol) & [77] \\
\hline & & Suspension (methanol) & {$[75]$} \\
\hline \multirow{2}{*}{ Intravaginal } & \multirow{2}{*}{ Vaginal infection } & Cream (o/w emulsion) & [70] \\
\hline & & Suspension & [79] \\
\hline Intravenous & Intravenous Candida infection & Solution (water) & {$[78]$} \\
\hline \multirow{7}{*}{ Orally } & $\begin{array}{l}\text { Anti-inflammation, } \\
\text { antinociceptive and would } \\
\text { healing potential } \\
\text { (incision/excision models) }\end{array}$ & Suspension ( $0.5 \%$ sodium carboxy methyl cellulose (CMC)) & {$[72]$} \\
\hline & Excision and incision wound & Suspension (extract in vehicle) & {$[74]$} \\
\hline & \multirow{2}{*}{ Immunomodulation } & Suspension ( $1 \%$ sodium carboxy methyl cellulose (CMC)) & {$[66]$} \\
\hline & & Suspension ( $1 \% \mathrm{w} / \mathrm{v}$ aqueous gum acacia) & {$[67]$} \\
\hline & Intravenous Candida infection & Solution (aqueous) & {$[76]$} \\
\hline & Oral cavity children affections & Mouthwash (water) & {$[81]$} \\
\hline & Subclinical mastitis & Crude extracts (cooked and powder leaves) & {$[80]$} \\
\hline \multirow{6}{*}{ Topically } & \multirow{2}{*}{$\begin{array}{l}\text { Excision and incision } \\
\text { wound }\end{array}$} & Ointment (vehicle) & [72] \\
\hline & & Cream (aqueous) & {$[71]$} \\
\hline & \multirow{4}{*}{ Excision wound } & Cream (aqueous) & [73] \\
\hline & & Ointment (w/w) & {$[69]$} \\
\hline & & Ointment (w/w) & {$[90]$} \\
\hline & & Ointment (vehicle) & {$[68]$} \\
\hline
\end{tabular}

It is convenient to highlight that the laboratorial formulations are specifically designed according to the examined clinical models; that is, for local/topical uses, creams, ointments, and also intravaginal administration comprise the first choice to evaluate the wound healing and antifungal potential in externally affected models, while suspensions, solutions, and mouthwashes are specifically indicated for internal uses (oral, intraperitoneal, and intravenous) in laboratorial models, such as in cases of induced systemic infections, immunomodulation, anti-inflammatory, and antinociceptive, and in some cases healing potential. In addition, in some phytochemical preparations, histological and histopathological studies were also carried out [68-75]. The evaluation of the tissues architecture between controls, pretreated and treated models, is of extreme relevance. The obtained results by these studies allow an effective determination of the toxic potential but also predict its possible types/ways of use, providing upcoming information related with its possible clinical applications.

\section{Conclusion and Future Perspectives}

Microorganisms are able to provide several benefits to the host (due to the establishment of symbiotic relationships) but are also responsible for severe health conditions. Antimicrobial agents are normally effective, but due to their overuse and related side effects and toxicity, its effectiveness has been seriously questioned. Plants phenolic extracts and isolated compounds possess a multitude of healing properties. Methanol, followed by acetone, water, ethanol, petroleum ether, methanol-dichloromethane, ethyl acetate, and n-butanol extracts obtained from leaves, seeds, fruits, and flowers comprise extremely enriched-phenolic sources. Despite the pool of phenolic compounds present in phytochemical preparations, only stilbenes (namely, pterostilbenes and riccardin D) and curcuminoids (curcumin and piperine) have been studied for their in vivo anti-Candida effects. Oral (suspension, solution, mouthwash, and crude extracts), followed by topical (ointment and cream), intraperitoneal (solution and suspension), intravaginal (cream, solution, and suspension), and intravenous (solution), phytochemical formulations were often prepared for in vivo administration.

In fact, phytochemicals are the basis for the design and development of new synthetic drugs, but while synthetic chemical drugs act by a single way, natural matrices are able to establish synergisms, antagonisms, and even polyvalence effects. In vitro studies are normally the first choice to evaluate the healing properties of natural matrices. However, in vivo studies present a higher importance, Once considers the organic metabolism and pharmacokinetic and pharmacodynamic parameters, among other factors.

Overall, and apart from the stated advances, upcoming specific clinical formulations, ways of administration, and therapeutic dosage need to be established, being clinical trials very important to deepen knowledge through more detailed in vivo studies. 


\section{Conflict of Interests}

The authors declare that they have no conflict of interests.

\section{Acknowledgments}

The authors are grateful to Foundation for Science and Technology (FCT, Portugal) for N. Martins Grant (SFRH/BD/87658/2012), L. Barros researcher contract under "Programa Compromisso com Ciência-2008," and financial support to the research centre CIMO (strategic project PEst-OE/AGR/UI0690/2014). This work was also supported by the Programa Operacional, Fatores de competitividade-COMPETE and by national funds through FCT (Fundação para a Ciência e a Tecnologia) on the scope of the Projects FCT PTDC/SAU-MIC/119069/2010, RECI/EBB-EBI/0179/2012, and PEst-OE/EQB/LA0023/2013. The authors thank the Project "BioHealth-Biotechnology and Bioengineering approaches to improve health quality," Ref. NORTE-07-0124-FEDER-000027, cofunded by the Programa Operacional Regional do Norte (ON.2-O Novo Norte), QREN, and FEDER.

\section{References}

[1] E. A. Palombo, "Traditional medicinal plant extracts and natural products with activity against oral bacteria: potential application in the prevention and treatment of oral diseases," Evidence-Based Complementary and Alternative Medicine, vol. 2011, Article ID 680354, 15 pages, 2011.

[2] A. Sher, "Antimicrobial activity of natural products from medicinal plants," Gomal Journal of Medical Sciences, vol. 7, no. 1, pp. 72-78, 2009.

[3] L. Rubió, M.-J. Motilva, and M.-P. Romero, "Recent advances in biologically active compounds in herbs and spices: a review of the most effective antioxidant and anti-inflammatory active principles," Critical Reviews in Food Science and Nutrition, vol. 53, no. 9, pp. 943-953, 2013.

[4] O. A. Ogundare, "The antimicrobial pattern and phytochemical properties of the leaf extracts of Senna podocarpa," African Journal of Microbiology Research, vol. 3, no. 7, pp. 400-406, 2009.

[5] D. S. Alviano and C. S. Alviano, "Plant extracts: search for new alternatives to treat microbial diseases," Current Pharmaceutical Biotechnology, vol. 10, no. 1, pp. 106-121, 2009.

[6] G. Lopes, E. Pinto, P. B. Andrade, and P. Valentão, "Antifungal activity of phlorotannins against dermatophytes and yeasts: approaches to the mechanism of action and influence on Candida albicans virulence factor," PLoS ONE, vol. 8, no. 8, Article ID e72203, 2013.

[7] B. B. Mishra and V. K. Tiwari, "Natural products: an evolving role in future drug discovery," European Journal of Medicinal Chemistry, vol. 46, no. 10, pp. 4769-4807, 2011.

[8] M. N. Asl and H. Hosseinzadeh, "Review of pharmacological effects of Glycyrrhiza sp. and its bioactive compounds," Phytotherapy Research, vol. 22, no. 6, pp. 709-724, 2008.

[9] N. Martins, I. C. F. R. Ferreira, L. Barros, S. Silva, and M. Henriques, "Candidiasis: predisposing factors, prevention, diagnosis and alternative treatment," Mycopathologia, vol. 177, no. 5-6, pp. 223-240, 2014.
[10] T. C. White, K. A. Marr, and R. A. Bowden, "Clinical, cellular, and molecular factors that contribute to antifungal drug resistance," Clinical Microbiology Reviews, vol. 11, no. 2, pp. 382-402, 1998.

[11] D. S. Perlin, "Resistance to echinocandin-class antifungal drugs," Drug Resistance Updates, vol. 10, no. 3, pp. 121-130, 2007.

[12] D. P. Kontoyiannis and R. E. Lewis, "Antifungal drug resistance of pathogenic fungi," The Lancet, vol. 359, no. 9312, pp. 11351144, 2002.

[13] P. Mašković, S. Solujić, V. Mihailović et al., "Phenolic compounds and biological activity of Kitaibelia vitifolia," Journal of Medicinal Food, vol. 14, no. 12, pp. 1617-1623, 2011.

[14] E. Grotewold, The Science of Flavonoids, Ohio State University, Colombus, Ohio, USA, 2006.

[15] T. Arif, J. D. Bhosale, N. Kumar et al., "Natural productsantifungal agents derived from plants," Journal of Asian Natural Products Research, vol. 11, no. 7, pp. 621-638, 2009.

[16] M. Friedman, "Overview of antibacterial, antitoxin, antiviral, and antifungal activities of tea flavonoids and teas," Molecular Nutrition and Food Research, vol. 51, no. 1, pp. 116-134, 2007.

[17] B. Özçelik, M. Kartal, and I. Orhan, "Cytotoxicity, antiviral and antimicrobial activities of alkaloids, flavonoids, and phenolic acids," Pharmaceutical Biology, vol. 49, no. 4, pp. 396-402, 2011.

[18] M. Zabka and R. Pavela, "Antifungal efficacy of some natural phenolic compounds against significant pathogenic and toxinogenic filamentous fungi," Chemosphere, vol. 93, no. 6, pp. 10511056, 2013.

[19] N. Martins, L. Barros, M. Henriques, S. Silva, and I. C. Ferreira, "Activity of phenolic compounds from plant origin against Candida species," Industrial Crops and Products, vol. 74, pp. 648-670, 2015.

[20] C. Cueva, M. V. Moreno-Arribas, P. J. Martín-Álvarez et al., "Antimicrobial activity of phenolic acids against commensal, probiotic and pathogenic bacteria," Research in Microbiology, vol. 161, no. 5, pp. 372-382, 2010.

[21] A. Scalbert, S. Deprez, I. Mila, A.-M. Albrecht, J.-F. Huneau, and S. Rabot, "Proanthocyanidins and human health: systemic effects and local effects in the gut," BioFactors, vol. 13, no. 1-4, pp. 115-120, 2000.

[22] M. T. Murray and J. Pizzorno, The Encyclopedia of Natural Medicine, Atria Books, New York, NY, USA, 2012.

[23] P. A. Balch, Prescription for Nutritional Healing, Penguin Group, London, UK, 2006.

[24] M. T. Murray and J. Pizzorno, The Encyclopedia of Healing Foods, Simon and Schuster, New York, NY, USA, 2005.

[25] J. D. Sobel, "Vulvovaginal candidosis," The Lancet, vol. 369, no. 9577, pp. 1961-1971, 2007.

[26] T. J. Lott, R. E. Fundyga, R. J. Kuykendall, and J. Arnold, “The human commensal yeast, Candida albicans, has an ancient origin," Fungal Genetics and Biology, vol. 42, no. 5, pp. 444-451, 2005.

[27] J. Kim and P. Sudbery, "Candida albicans, a major human fungal pathogen," Journal of Microbiology, vol. 49, no. 2, pp. 171-177, 2011.

[28] M. Develoux and S. Bretagne, "Candidoses et levuroses diverses," EMC Maladies Infectieuses, vol. 2, no. 3, pp. 119-139, 2005.

[29] G. García-Elorriaga and G. Rey-pineda, "Nutrition and intestinal microflora," Journal of Nutritional Therapeutics, vol. 2, no. 55, pp. 112-121, 2013. 
[30] A. A. Amara and A. Shibl, "Role of Probiotics in health improvement, infection control and disease treatment and management," Saudi Pharmaceutical Journal, vol. 23, no. 2, pp. 107-114, 2013.

[31] J. F. Balch and M. Stengler, Prescription for Natural Cures, Wiley, Hoboken, NJ, USA, 2004.

[32] J. Balch, M. Stengler, and R. Balch, Prescription for Drug Alternatives: All-Natural Options for Better Health without the Side Effects, John Wiley \& Sons, New York, NY, USA, 2008.

[33] J. B. Epstein and B. Polsky, "Oropharyngeal candidiasis: a review of its clinical spectrum and current therapies," Clinical Therapeutics, vol. 20, no. 1, pp. 40-57, 1998.

[34] A. T. Sangamwar, U. D. Deshpande, and S. S. Pekamwar, "Antifungals: need to search for a new molecular target," Indian Journal of Pharmaceutical Sciences, vol. 70, no. 4, pp. 423-430, 2008.

[35] A. Lupetti, P. H. Nibbering, M. Campa, M. Del Tacca, and R. Danesi, "Molecular targeted treatments for fungal infections: the role of drug combinations," Trends in Molecular Medicine, vol. 9, no. 6, pp. 269-276, 2003.

[36] B. M. Alphonsa, P. T. S. Kumar, G. Praveen, R. Biswas, K. P. Chennazhi, and R. Jayakumar, "Antimicrobial drugs encapsulated in fibrin nanoparticles for treating microbial infested wounds," Pharmaceutical Research, vol. 31, no. 5, pp. 1338-1351, 2014.

[37] Z. Jiang, J. Gu, C. Wang et al., "Design, synthesis and antifungal activity of novel triazole derivatives containing substituted 1,2,3triazole-piperdine side chains," European Journal of Medicinal Chemistry, vol. 82, pp. 490-497, 2014.

[38] E. Lastauskiene, A. Zinkevičiene, I. Girkontaite, A. Kaunietis, and V. Kvedariene, "Formic acid and acetic acid induce a programmed cell death in pathogenic Candida species," Current Microbiology, vol. 69, no. 3, pp. 303-310, 2014.

[39] C. L. Donnici, L. J. Nogueira, M. H. Araujo et al., "In vitro studies of the activity of dithiocarbamate organoruthenium complexes against clinically relevant fungal pathogens," Molecules, vol. 19, no. 4, pp. 5402-5420, 2014.

[40] S. Wu, Y. Zhang, X. He et al., "From antidiabetic to antifungal: discovery of highly potent triazole-thiazolidinedione hybrids as novel antifungal agents," ChemMedChem, vol. 9, no. 12, pp. 2639-2646, 2014.

[41] N. Martins, L. Barros, C. Santos-Buelga, M. Henriques, S. Silva, and I. C. F. R. Ferreira, "Evaluation of bioactive properties and phenolic compounds in different extracts prepared from Salvia officinalis L.," Food Chemistry, vol. 170, pp. 378-385, 2015.

[42] S.-S. Wang, D.-M. Wang, W.-J. Pu, and D.-W. Li, "Phytochemical profiles, antioxidant and antimicrobial activities of three Potentilla species," BMC Complementary and Alternative Medicine, vol. 13, article 321, 2013.

[43] W. M. Otang, D. S. Grierson, and R. N. Ndip, "Phytochemical studies and antioxidant activity of two South African medicinal plants traditionally used for the management of opportunistic fungal infections in HIV/AIDS patients," BMC Complementary and Alternative Medicine, vol. 12, no. 1, article 43, 2012.

[44] S. Kirbag, F. Zengin, and M. Kursat, "Antimicrobial activities of extracts of some plants," Pakistan Journal of Botany, vol. 41, no. 4, pp. 2067-2070, 2009.

[45] M. M. Cowan, "Plant products as antimicrobial agents," Clinical Microbiology Reviews, vol. 12, no. 4, pp. 564-582, 1999.

[46] M. Saleem, M. Nazir, M. S. Ali et al., "Antimicrobial natural products: an update on future antibiotic drug candidates," Natural Product Reports, vol. 27, no. 2, pp. 238-254, 2010.
[47] B. B. Petrovska, "Historical review of medicinal plants' usage," Pharmacognosy Reviews, vol. 6, no. 11, pp. 1-5, 2012.

[48] B. Mahesh and S. Satish, "Antimicrobial activity of some important medicinal plant against plant and human pathogens," World Journal of Agricultural Sciences, vol. 4, supplement 1, pp. 839-843, 2008.

[49] A. Mathur, R. Singh, S. Yousuf et al., "Antifungal activity of some plant extracts against clinical pathogens," Advances in Applied Science Research, vol. 2, no. 2, pp. 260-264, 2011.

[50] N. C. C. Silva and A. Fernandes Júnior, "Biological properties of medicinal plants: a review of their antimicrobial activity," Journal of Venomous Animals and Toxins Including Tropical Diseases, vol. 16, no. 3, pp. 402-413, 2010.

[51] S. Shi and U. Klotz, "Drug interactions with herbal medicines," Clinical Pharmacokinetics, vol. 51, no. 2, pp. 77-104, 2012.

[52] Z. Hu, X. Yang, P. C. L. Ho et al., "Herb-drug interactions: a literature review," Drugs, vol. 65, no. 9, pp. 1239-1282, 2005.

[53] B. J. Gurley, E. K. Fifer, and Z. Gardner, "Pharmacokinetic herbdrug interactions (Part 2): drug interactions involving popular botanical dietary supplements and their clinical relevance," Planta Medica, vol. 78, no. 13, pp. 1490-1514, 2012.

[54] J. Rose, "Herbal and nutritional support for the immune system," Clinical Nutrition Insight, vol. 6, no. 2, pp. 1-4, 1999.

[55] M. T. Murray, The Healing Power of Herbs, Random House, New York, NY, USA, 2004.

[56] M. S. Greenberg and M. Glick, Burket's Oral Medicine: Diagnosis and Treatment, BC Decker, New York, NY, USA, 2003.

[57] P. R. Murray, K. S. Rosenthal, and M. A. Pfaller, Medical Microbiology, 2012.

[58] D. Vázquez-González, A. M. Perusquía-Ortiz, M. Hundeiker, and A. Bonifaz, "Opportunistic yeast infections: candidiasis, cryptococcosis, trichosporonosis and geotrichosis," Journal of the German Society of Dermatology, vol. 11, no. 5, pp. 381-395, 2013.

[59] L. J. Nohynek, H.-L. Alakomi, M. P. Kähkönen et al., "Berry phenolics: antimicrobial properties and mechanisms of action against severe human pathogens," Nutrition and Cancer, vol. 54, no. 1, pp. 18-32, 2006.

[60] J.-D. Zhang, Z. Xu, Y.-B. Cao et al., "Antifungal activities and action mechanisms of compounds from Tribulus terrestris L.," Journal of Ethnopharmacology, vol. 103, no. 1, pp. 76-84, 2006.

[61] J. Cheel, L. Tůmová, C. Areche et al., "Variations in the chemical profile and biological activities of licorice (Glycyrrhiza glabra L.), as influenced by harvest times," Acta Physiologiae Plantarum, vol. 35, no. 4, pp. 1337-1349, 2013.

[62] P. Montoro, M. Maldini, M. Russo, S. Postorino, S. Piacente, and C. Pizza, "Metabolic profiling of roots of liquorice (Glycyrrhiza glabra) from different geographical areas by ESI/MS/MS and determination of major metabolites by LC-ESI/MS and LCESI/MS/MS," Journal of Pharmaceutical and Biomedical Analysis, vol. 54, no. 3, pp. 535-544, 2011.

[63] N. Trabelsi, P. Waffo-Téguo, M. Snoussi et al., "Variability of phenolic composition and biological activities of two Tunisian halophyte species from contrasted regions," Acta Physiologiae Plantarum, vol. 35, no. 3, pp. 749-761, 2013.

[64] M. I. Dias, L. Barros, M. J. Sousa, and I. C. F. R. Ferreira, "Comparative study of lipophilic and hydrophilic antioxidants from in vivo and in vitro grown Coriandrum sativum," Plant Foods for Human Nutrition, vol. 66, no. 2, pp. 181-186, 2011.

[65] R. F. Martino, R. C. Davicino, M. A. Mattar, Y. A. Casali, S. G. Correa, and B. Micalizzi, "In vivo effect of three fractions of 
Larrea divaricata Cav. (jarilla) on the innate immune system: Macrophage response against Candida albicans," Mycoses, vol. 54, no. 6, pp. e718-e725, 2011.

[66] S. S. Heroor, A. K. Beknal, and N. Mahurkar, "Immunomodulatory activity of methanolic extracts of fruits and bark of Ficus glomerata Roxb. in mice and on human neutrophils," Indian Journal of Pharmacology, vol. 45, no. 2, pp. 130-135, 2013.

[67] S. Kumar, G. Sharma, T. Sidiq et al., "Immunomodulatory potential of a bioactive fraction from the leaves of Phyllostachys bambusoides (Bamboo) in BALB/C mice," EXCLI Journal, vol. 13, pp. 137-150, 2014.

[68] E. A. Hayouni, K. Miled, S. Boubaker et al., "Hydroalcoholic extract based-ointment from Punica granatum L. peels with enhanced in vivo healing potential on dermal wounds," Phytomedicine, vol. 18, no. 11, pp. 976-984, 2011.

[69] W.-C. Chen, S.-S. Liou, T.-F. Tzeng, S.-L. Lee, and I.-M. Liu, "Wound repair and anti-inflammatory potential of Lonicera japonica in excision wound-induced rats," BMC Complementary and Alternative Medicine, vol. 12, no. 1, article 226, 2012.

[70] M. G. F. Araújo, M. Pacífico, W. Vilegas et al., "Evaluation of Syngonanthus nitens (Bong.) Ruhl. extract as antifungal and in treatment of vulvovaginal candidiasis," Medical Mycology, vol. 51, no. 7, pp. 673-682, 2013.

[71] P. Masoko, J. Picard, R. L. Howard, L. J. Mampuru, and J. N. Eloff, "In vivo antifungal effect of Combretum and Terminalia species extracts on cutaneous wound healing in immunosuppressed rats," Pharmaceutical Biology, vol. 48, no. 6, pp. 621-632, 2010.

[72] A. Güvenç, E. K. Akkol, I. Süntar, H. Keleş, S. Yildiz, and I. Çaliş, "Biological activities of Pseudevernia furfuracea (L.) Zopf extracts and isolation of the active compounds," Journal of Ethnopharmacology, vol. 144, no. 3, pp. 726-734, 2012.

[73] C. Agyare, S. B. Bempah, Y. D. Boakye, P. G. Ayande, M. Adarkwa-Yiadom, and K. B. Mensah, "Evaluation of antimicrobial and wound healing potential of Justicia flava and Lannea welwitschii," Evidence-Based Complementary and Alternative Medicine, vol. 2013, Article ID 632927, 10 pages, 2013.

[74] P. Roy, S. Amdekar, A. Kumar, R. Singh, P. Sharma, and V. Singh, "In vivo antioxidative property, antimicrobial and wound healing activity of flower extracts of Pyrostegia venusta (Ker Gawl) Miers," Journal of Ethnopharmacology, vol. 140, no. 1, pp. 186-192, 2012.

[75] G. Sahgal, S. Ramanathan, S. Sasidharan, M. N. Mordi, S. Ismail, and S. M. Mansor, "In vitro and in vivo anticandidal activity of Swietenia mahogani methanolic seed extract," Tropical Biomedicine, vol. 28, no. 1, pp. 132-137, 2011.

[76] S. Vijayarathna, Z. Zakaria, Y. Chen, L. Y. Latha, J. R. Kanwar, and S. Sasidharan, "The antimicrobial efficacy of elaeis guineensis: characterization, in vitro and in vivo Studies," Molecules, vol. 17, no. 5, pp. 4860-4877, 2012.

[77] S. L. Jothy, Z. Zakariah, Y. Chen, and S. Sasidharan, "In vitro, in situ and in vivo studies on the anticandidal activity of Cassia fistula seed extract," Molecules, vol. 17, no. 6, pp. 6997-7009, 2012.

[78] J. P. Dzoyem, R. T. Tchuenguem, J. R. Kuiate, G. N. Teke, F. A. Kechia, and V. Kuete, "In vitro and in vivo antifungal activities of selected Cameroonian dietary spices," BMC Complementary \& Alternative Medicine, vol. 14, article 58, 2014.

[79] G. Simonetti, A. R. Santamaria, F. D. D’Auria et al., "Evaluation of anti-Candida activity of Vitis vinifera L. seed extracts obtained from wine and table cultivars," BioMed Research International, vol. 2014, Article ID 127021, 11 pages, 2014.
[80] D. Abaineh and A. Sintayehu, "Treatment trial of subclinical mastitis with the herb Persicaria senegalense (Polygonaceae)," Tropical Animal Health and Production, vol. 33, no. 6, pp. 511$519,2001$.

[81] N. Chelli-Chentouf, A. T. T. Meddah, C. Mullié, A. Aoues, and B. Meddah, "In vitro and in vivo antimicrobial activity of Algerian Hoggar Salvadora persica L. extracts against microbial strains from children's oral cavity," Journal of Ethnopharmacology, vol. 144, no. 1, pp. 57-66, 2012.

[82] D. T. Veličković, I. T. Karabegović, S. S. Stojičević, M. L. Lazić, V. D. Marinković, and V. B. Veljković, "Comparison of antioxidant and antimicrobial activities of extracts obtained from Salvia glutinosa L. and Salvia officinalis L.," Hemijska Industrija, vol. 65, no. 5, pp. 599-605, 2011.

[83] D. S. Bashi, B. S. Fazly Bazzaz, A. Sahebkar, M. M. Karimkhani, and A. Ahmadi, "Investigation of optimal extraction, antioxidant, and antimicrobial activities of Achillea biebersteinii and A. wilhelmsii," Pharmaceutical Biology, vol. 50, no. 9, pp. 1168-1176, 2012.

[84] A. Parsaeimehr, E. Sargsyan, and K. Javidnia, "A comparative study of the antibacterial, antifungal and antioxidant activity and total content of phenolic compounds of cell cultures and wild plants of three endemic species of Ephedra," Molecules, vol. 15, no. 3, pp. 1668-1678, 2010.

[85] B. A. Lone, S. A. Bandh, M. Z. Chishti, F. A. Bhat, H. Tak, and H. Nisa, "Anthelmintic and antimicrobial activity of methanolic and aqueous extracts of Euphorbia helioscopia L.," Tropical Animal Health and Production, vol. 45, no. 3, pp. 743-749, 2013.

[86] D.-D. Li, L.-X. Zhao, E. Mylonakis et al., "In vitro and in vivo activities of pterostilbene against Candida albicans biofilms," Antimicrobial Agents and Chemotherapy, vol. 58, no. 4, pp. 2344-2355, 2014.

[87] Y. Li, Y. Ma, L. Zhang et al., "In vivo inhibitory effect on the biofilm formation of Candida albicans by liverwort derived riccardin D," PLoS ONE, vol. 7, no. 4, Article ID e35543, 2012.

[88] M. Sharma, R. Manoharlal, N. Puri, and R. Prasad, "Antifungal curcumin induces reactive oxygen species and triggers an early apoptosis but prevents hyphae development by targeting the global repressor TUP1 in Candida albicans," Bioscience Reports, vol. 30, no. 6, pp. 391-404, 2010.

[89] B. Vanaclocha and S. Cañigueral, Fitoterapia: Vademecum de Prescripción, Elsevier España, Barcelona, Spain, 2003.

[90] S. Y. Gbedema, K. Emelia, A. Francis, A. Kofi, and W. Eric, "Wound healing properties and kill kinetics of Clerodendron splendens G. Don, a Ghanaian wound healing plant," Pharmacognosy Research, vol. 2, no. 2, pp. 63-68, 2010. 

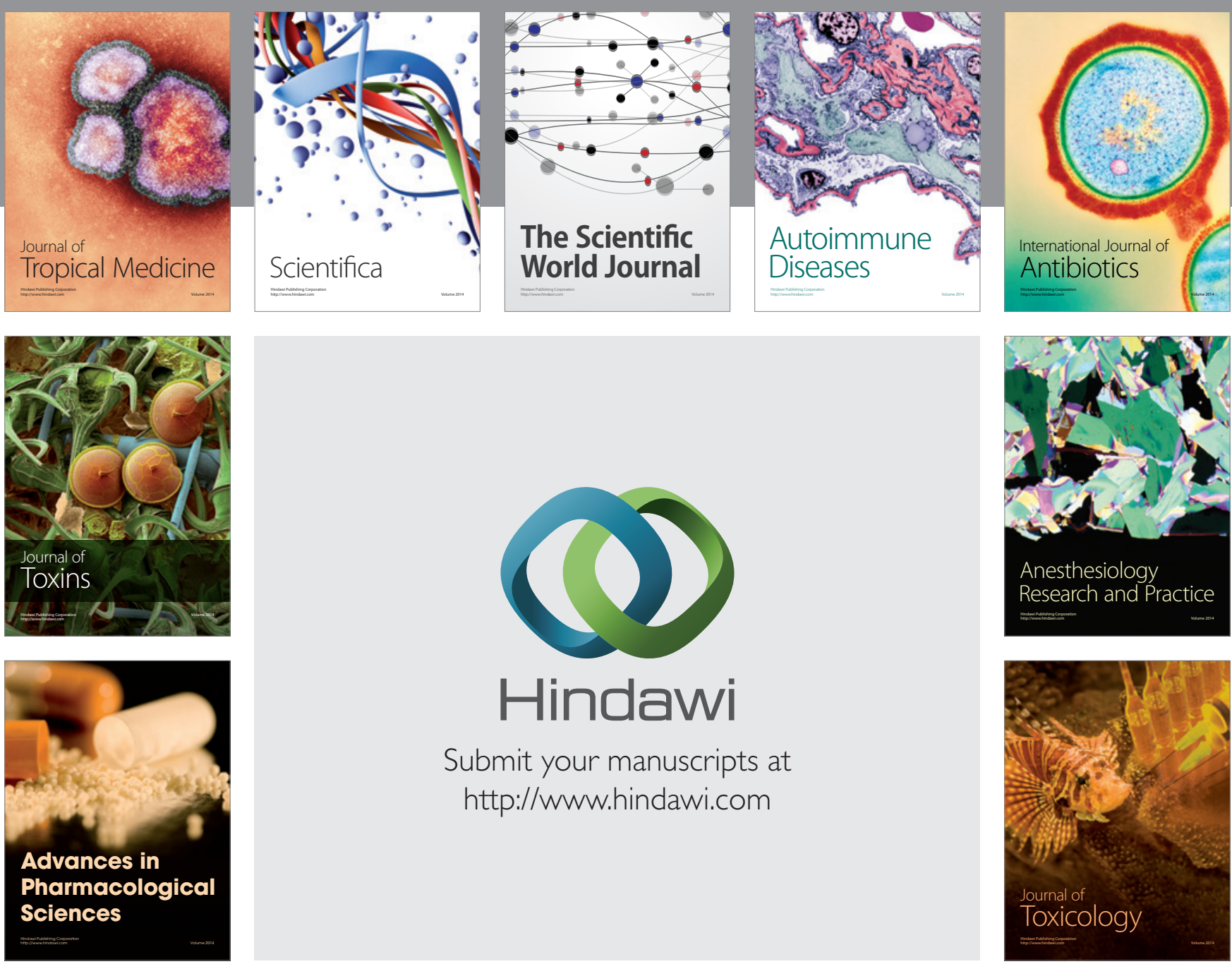

\section{Hindawi}

Submit your manuscripts at

http://www.hindawi.com
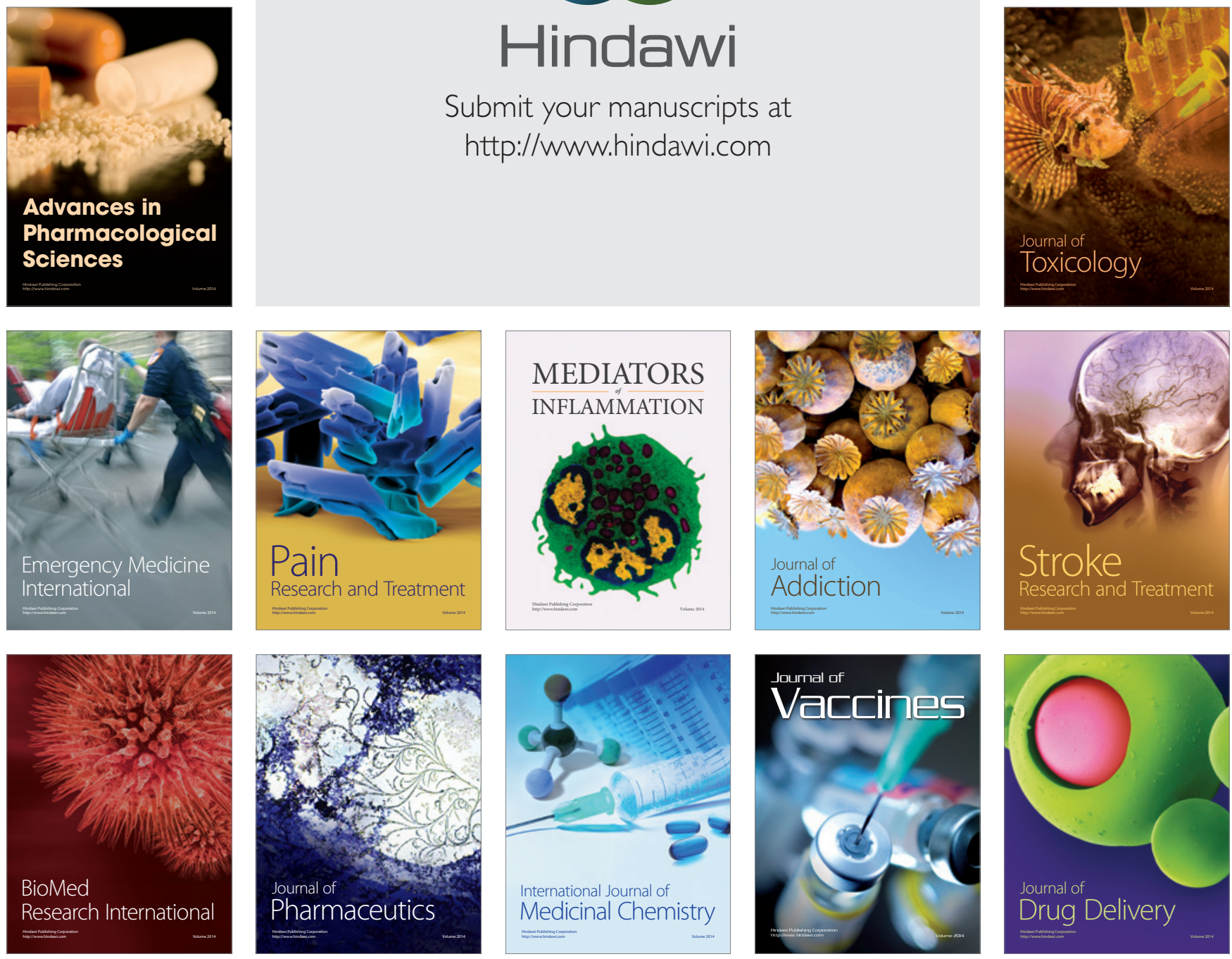